\title{
Characterization of Al-Cu alloy reinforced fly ash metal matrix composites by squeeze casting method
}

\author{
G. N. Lokesh ${ }^{1 *}$, M. Ramachandra ${ }^{2}$, K. V. Mahendra ${ }^{3}$, T. Sreenith ${ }^{1}$ \\ ${ }^{1 *}$ Department of Mechanical Engineering, Acharya Institute of Technology, Bangalore-560107, INDIA \\ ${ }^{2}$ Mechanical Department, BMS College of Engineering, Bangalore-560019, INDIA \\ ${ }^{3}$ Mechanical Department, Jyothy Institute of Technology, Kanakapura Road, Bangalore-560062, INDIA \\ "Corresponding Author: e-mail: lokeshgn32@gmail.com
}

\begin{abstract}
Metal matrix composites (MMCs) are of great interest in industrial applications for lighter materials with high specific strength, stiffness and heat resistance. The processing of MMCs by casting process is a very promising way of manufacturing near net shape composites at relatively low cost. The liquid metallurgy squeeze casting technique has characteristics such as fine microstructure as a result of rapid cooling, low porosity and good bonding between the particles and base alloy. In this study, the effect of hardness, tensile, compression and impact properties as well as density have been investigated. The Al-4.5wt $\% \mathrm{Cu}$ alloy was chosen as base matrix casted by both stir and squeeze casting. Fly ash is one of the most inexpensive and low density reinforcement available in large quantities as solid waste is used as reinforcement. The Al-4.5wt\%Cu reinforced 3, 6, 9 and $12 \mathrm{wt} \%$ fly ash composite was squeeze casted with an applied pressure of $120 \mathrm{MPa}$. The results showed that hardness tensile compression and impact values were increased by increasing weight percentage of fly ash reinforcements during squeeze casting. Porosity and other casting defects such as shrinkage cavities were minimised due to pressure applied during solidification. Increase in weight percentage of fly ash composites caused to increase porosity even in squeeze casting but lesser than gravity cast matrix alloy. Microstructure shows the absence of micro porosity, and grain refinement interfacial bond between matrix and reinforcement.
\end{abstract}

Keywords: Metal matrix composite, squeeze casting and fly ash.

DOI: http://dx.doi.org/10.4314/ijest.v5i4.7

\section{Introduction}

The physical and mechanical properties of Aluminium-based MMCs have made them attractive materials for automotive and aerospace applications (Kretschmer, 1988; Ibrahim et al., 1991; Surappa., 1997). Cost is the key factor for their wider application in modern industry, although potential benefits in weight reduction, increased composites life and improved recyclability should be taken into account (Klimowicz., 1994; Hashim et al., 2001). Even today MMCs are still significantly more expensive than their competitors. Cost reductions can be achieved only by simpler fabrication methods, higher production volumes and cheaper reinforcements (Shorowordi et al., 2003). Among various discontinues disperoids used, fly ash is one of the most inexpensive and low density reinforcement available in large quantities as solid waste by product during combustion of coal in thermal power plant (Dhadse et al., 2008). Addition of fly ash particle as reinforcement in MMCs is advantages for obtaining higher structural homogeneity with minimum possible porosity levels, good interfacial bonding, higher mechanical strength, uniform distribution of reinforcement and act as a load bearing constituents (Rohatgi et al., 1997; Ogel et al., 2001; Rohatgi et al., 2006; Onat et al., 2007). In the present investigation $\mathrm{Al}-4.5 \mathrm{wt} \% \mathrm{Cu}$ alloy as base matrix is casted by both gravity and squeeze casting. Different weight percentage of fly ash particulates is reinforced by squeeze casting route. The liquid casting mainly squeeze casting is preferred as it is the simplest, cheapest and persuadable to mass production. The samples obtained were tested for hardness, 
tensile, compression, impact strength and density. Micro photographs have been carried out to investigate the particle-matrix interface.

\section{Experimental work}

In the present work, squeeze casting system was constructed to produce specimens. A die and plunger was designed and made of cast iron for die and tool steel for plunger. Melting of base alloy, degassing and additions of particulates were performed in an electrically resistance heated furnace. Graphite crucible was used for melting of matrix alloy, and the addition and mixing of particulates were made into the melt in the crucible. For squeeze casting operations a constant $120 \mathrm{MPa}$ pressure was used for unreinforced matrix alloy and the composites. Al- $4.5 \mathrm{wt} \% \mathrm{Cu}$ alloy was additionally produced by a gravity die casting method into a cast iron mould heated to around $380^{\circ} \mathrm{C}$ to compare the properties with squeeze cast unreinforced alloy. $\mathrm{Al}-4.5 \mathrm{wt} \% \mathrm{Cu}$ alloy was chosen as matrix alloy because of its widespread commercial applications. To increase casting fluidity and wetting between fly ash particles and the matrix, $0.5 \mathrm{wt} \% \mathrm{Mg}$ was also added to the matrix melt. The chemical composition, analysed by a Bairdas DV-6S optical emission spectrometer, is given in Table 1.

Table 1. The chemical composition of the matrix alloy (wt \%.)

\begin{tabular}{|c|c|c|c|c|c|c|c|c|c|c|}
\hline $\mathrm{Cu}$ & $\mathrm{Mg}$ & $\mathrm{Si}$ & $\mathrm{Fe}$ & $\mathrm{Mn}$ & $\mathrm{Ni}$ & $\mathrm{Pb}$ & $\mathrm{Sn}$ & $\mathrm{Ti}$ & $\mathrm{Zn}$ & $\mathrm{Al}$ \\
\hline 4.51 & 0.061 & 0.52 & 0.59 & 0.13 & 0.06 & 0.03 & 0.02 & 0.012 & 0.12 & balance \\
\hline
\end{tabular}

Four composites were produced by introducing fly ash particles with 3,6,9 and $12 \mathrm{wt} \%$ fly ash to the Al-Cu matrix alloy. The density of fly ash measured is $2.09 \mathrm{~g} / \mathrm{cm}^{3}$ with the particle size varying between 49 and $60 \mu \mathrm{m}$ and chemical composition of fly ash is given in Table 2 .

Table 2. The chemical composition of fly ash (wt \%.)

\begin{tabular}{|c|c|c|c|c|}
\hline $\mathrm{Al}_{2} \mathrm{O}_{3}$ & $\mathrm{SiO}_{2}$ & $\mathrm{Fe}_{2} \mathrm{O}_{3}$ & $\mathrm{TiO}_{2}$ & $\begin{array}{c}\text { Loss on } \\
\text { ignition }\end{array}$ \\
\hline 30.40 & 58.41 & 8.44 & 2.75 & 1.43 \\
\hline
\end{tabular}

A stir casting setup which consisted of a resistance furnace and a stirrer assembly is used to synthesis the composite. Al$4.5 \mathrm{wt} \% \mathrm{Cu}$ alloy commercially prepared was melted in a resistance heated muffle furnace and casted in a clay graphite crucible. The temperature of the melting is increased to $750^{\circ} \mathrm{C}$ and it is degassed by cleansed with hexachloroethane tablets. Then the molten metal was stirred to create a vortex and the reinforcements were added. The stirrer is maintained approximately 450rpm. The preheated fly ash particles were slowly added into the melt with $\mathrm{Mg}(0.5 \mathrm{wt} \%)$ were also added to ensure good wettability of particles. The stirred dispersed molten metal so obtained was then poured into preheated die cavity. Graphite lubricated die and plunger were preheated to $350^{\circ} \mathrm{C}$ to avoid premature chilling. Solidification was carried out under the pressure of $120 \mathrm{MPa}$ for a period of 60 to 90 seconds. Specimens of the unreinforced matrix alloy were also squeeze cast under identical conditions. Furthermore, a sample of the unreinforced matrix alloy was produced by gravity die casting in order to determine pressure effects on density of composites.

Squeeze casting specimens and unreinforced matrix alloys produced by both gravity and squeeze were cut to prepare samples for mechanical tests and metallographic examinations. Hardness measurement was carried out using a Brinell hardness tester. Before testing, specimen surfaces were polished using emery papers of 1000 mesh. An average of 6 measurements was taken for each sample to find the hardness value. Tensile test samples having $6 \mathrm{~mm}$ diameter with a gauge length of $25 \mathrm{~mm}$, were prepared for testing in Tensometer. Compression strengths were determined using a computerized UTM with an electronic extensometer as per ASTM E-8 standards. Online plotting of load versus extension was done continuously through a data acquisition system. Impact specimen was cut as per ASTM-E23 by diamond blade using CNC machine.

The microstructure of the composite after casting was examined to study the effect of fly ash percentage on polished section of each sample. The specimens were prepared for metallographic examinations using emery papers down to 3000mesh followed by polishing with diamond paste. Experimental density of composites and unreinforced matrix alloys were measured by water displacement technique and is calculated as:

$$
\rho_{E}=\frac{m}{V}
$$

Where $\rho_{E}$ is the experimental density of specimen, $m$ is the weight of the specimen and $V$ is the volume of water displaced. 
The theoretical density $\rho_{T}$ is measured from rule of mixture (ROM) and is given by (Meyers and Chawla, 1999):

$$
\rho_{T}=\rho_{m} V_{m}+\rho_{r} V_{r}
$$

Where, $\rho_{m}$ : Density of matrix, $V_{m}$ : Volume fraction of matrix, $\rho_{r}$ : Density of reinforcement and $V_{r}$ : Volume fraction of reinforcement.

The porosity was calculated as according to formula given below (Abtan, 2007):

$$
\text { Porosity }(\%)=\frac{\rho_{T-} \rho_{E}}{\rho_{T}} \mathrm{X} 100
$$

\section{Results and discussions}

\subsection{Density and porosity}

It is clear from the Table 2 that gravity cast specimen has the highest porosity of $6.79 \%$ due to microstructure defects raised from gravity casting. The lowest porosity obtained is squeeze cast matrix alloy, a recorded value of $2.13 \%$ and for composites, the lowest porosity obtained is $3.16 \%$ for $3 \mathrm{wt} \%$ fly ash and the highest porosity is $4.35 \%$ for $12 \mathrm{wt} \%$ fly ash reinforcement. The increase in density of composite may be due to reduction of micro porosity due to squeezing the casting during solidification (Suresh et al., 2003).

Table 2. Density and porosity measurements

\begin{tabular}{|c|c|c|c|c|c|}
\hline \multicolumn{2}{|c|}{ Sample } & Composition & $\begin{array}{c}\text { Theoretical } \\
\text { Density }\left(\mathrm{g} / \mathrm{cm}^{3}\right)\end{array}$ & $\begin{array}{c}\text { Experimental } \\
\text { Density }\left(\mathrm{g} / \mathrm{cm}^{3}\right)\end{array}$ & $\begin{array}{c}\text { Porosity } \\
(\%)\end{array}$ \\
\hline $\begin{array}{c}\text { Gravity cast } \\
\text { matrix alloy }\end{array}$ & Sample 1 & $\begin{array}{c}\text { Al-4.5wt\%.Cu } \\
\text { alloy }\end{array}$ & 2.7714 & 2.5831 & 6.79 \\
\hline $\begin{array}{c}\text { Squeeze cast } \\
\text { matrix alloy }\end{array}$ & Sample 2 & $\begin{array}{c}\text { Al-4.5wt\%.Cu } \\
\text { alloy }\end{array}$ & 2.7714 & 2.7122 & 2.13 \\
\hline Composite1 & Sample 3 & 3wt\%. Fly ash & 2.7451 & 2.6581 & 3.16 \\
\hline Composite2 & Sample 4 & 6wt\%. Fly ash & 2.7329 & 2.6410 & 3.36 \\
\hline Composite3 & Sample 5 & 9wt\%. Fly ash & 2.7213 & 2.6101 & 4.08 \\
\hline Composite4 & Sample 6 & 12wt\%. Fly ash & 2.7112 & 2.5932 & 4.35 \\
\hline
\end{tabular}

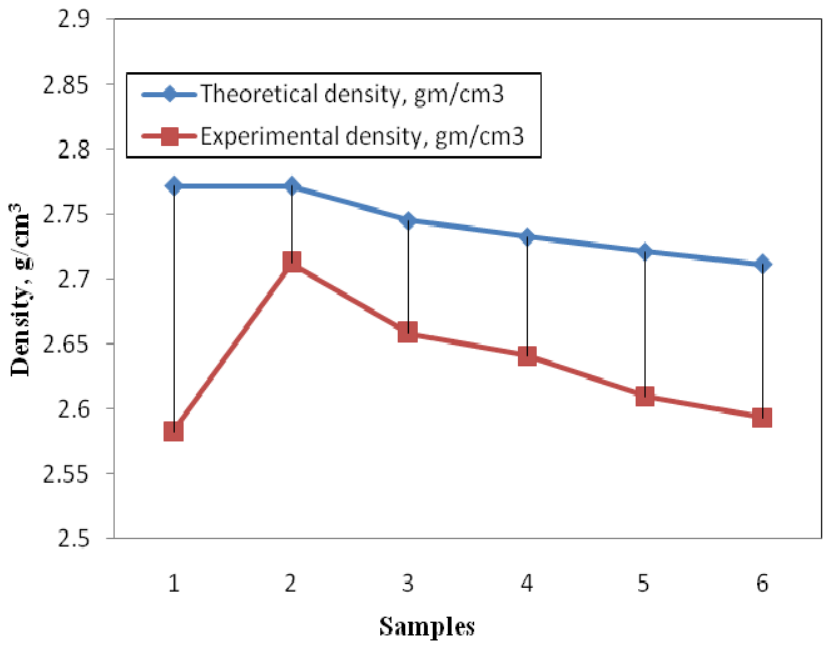

Figure 1. Density of gravity, squeeze cast and composite 
It is seen from Figure 1 that both theoretical and experimental density values are decreased with increased percentage of fly ash. Base alloy exhibit higher density value and addition of fly ash decreases the density of composites. This is because the density of fly ash is lesser than the base matrix alloy and as reinforcements occupies in matrix decreases the density of composite.

\subsection{Micrographs}

Figure 2 shows the optical microphotographs of fly ash particle reinforced MMCs. The specimens was moulded with acrylic cold setting compound and then ground with 80, 120, 220, 400, 600,1000 2000 and 3000grades of emery paper. The sample was electro polished and etched with Keller's reagent. Optical microphotographs show the uniform dispersion of the reinforcements in MMCs. The application of pressure can affect the virtual elimination of shrinkage and other voids and discontinuities. Therefore, pressure applied during solidification of an alloy can result in fine-grained equiaxed macro-structure with micro-structure being characterized by small dendrite arm spacing, small constituent particles and more homogeneous distribution of structural components. The matrix structure of the composite shows a smaller grain size then that of base alloy. After adding the matrix, there will be no change in the size of the flyash. Even during compaction in the squeeze casting, the particles adhere to the matrix. This can be clearly seen from the Scanning Electron Microscope (SEM) of squeeze casting specimen shown in Figure 3. The increasing percentage of fly ash leads to a finer grain size. These results may be due to the presence of fly ash which acts as sites of nucleation during solidification of the melt. The microstructure of this and similar composites shows the absence of voids and a uniform distribution of fly ash in the matrix structure.
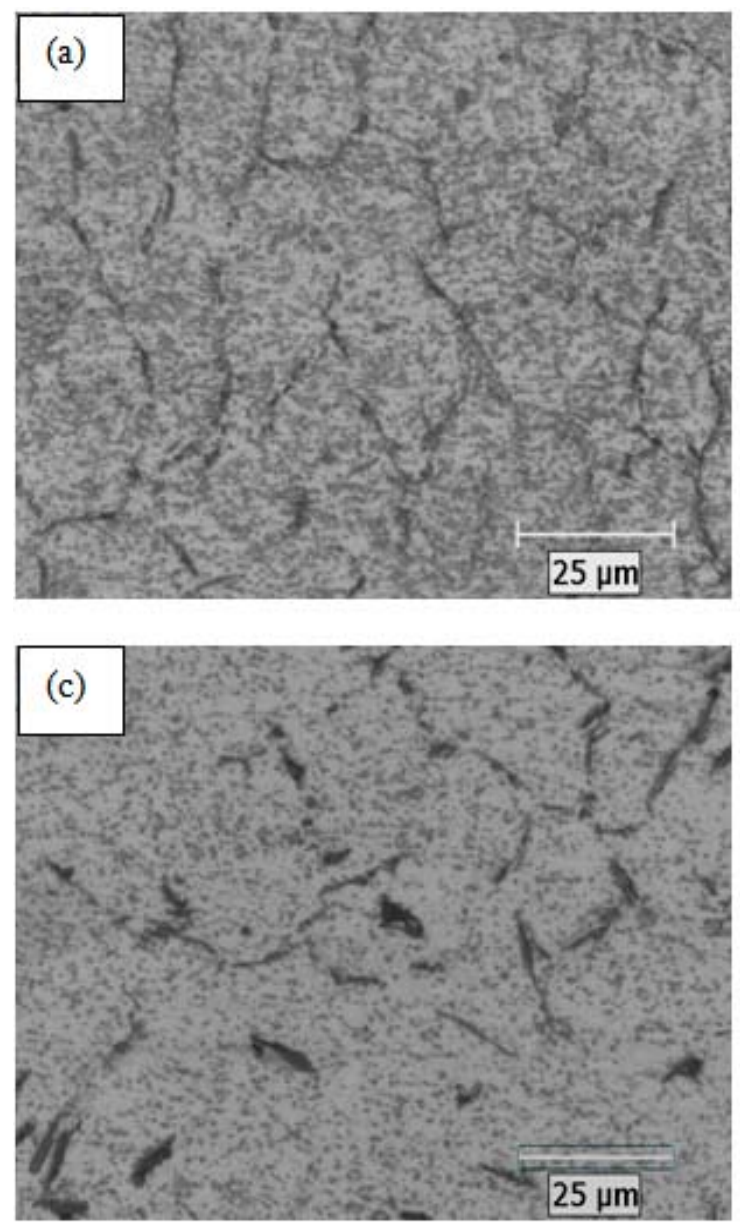
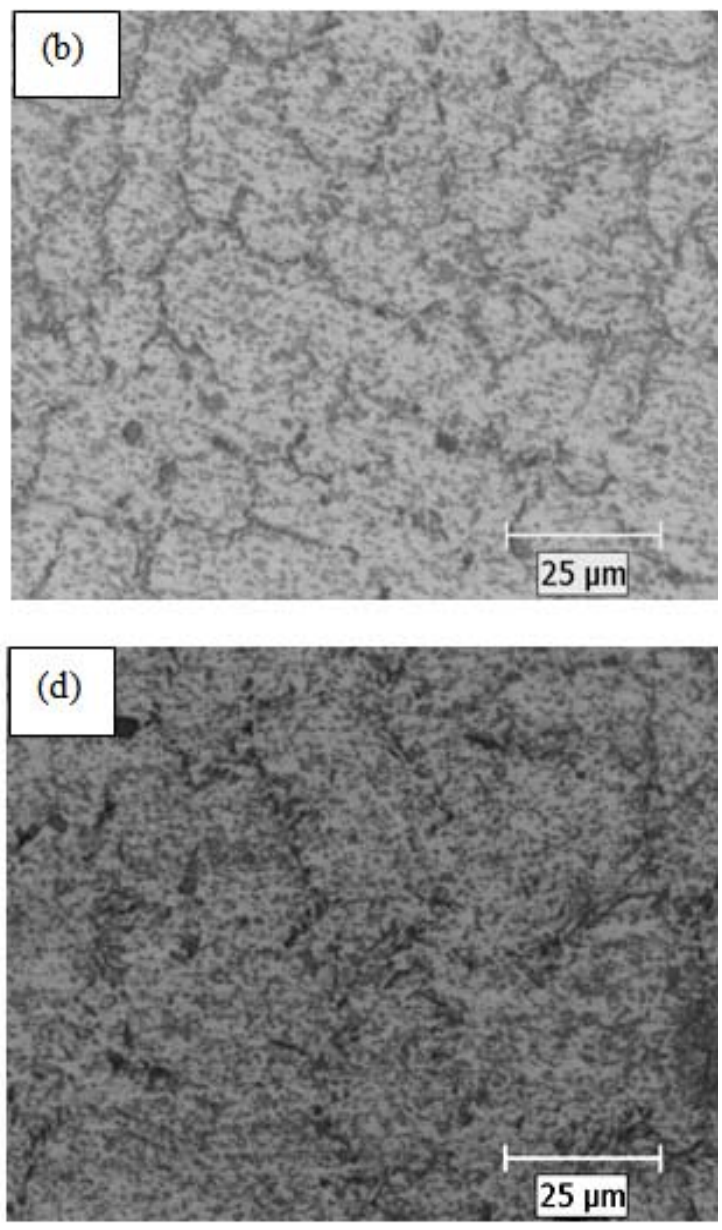

Figure 2. Optical microphotographs of Al-4.5wt $\% \mathrm{Cu}$ alloy reinforced fly ash: (a) base alloy gravity cast; (b) base alloy squeeze cast; (c) $6 \mathrm{wt} \%$ fly ash; and (d) $12 \mathrm{wt} \%$ fly ash squeeze cast. 


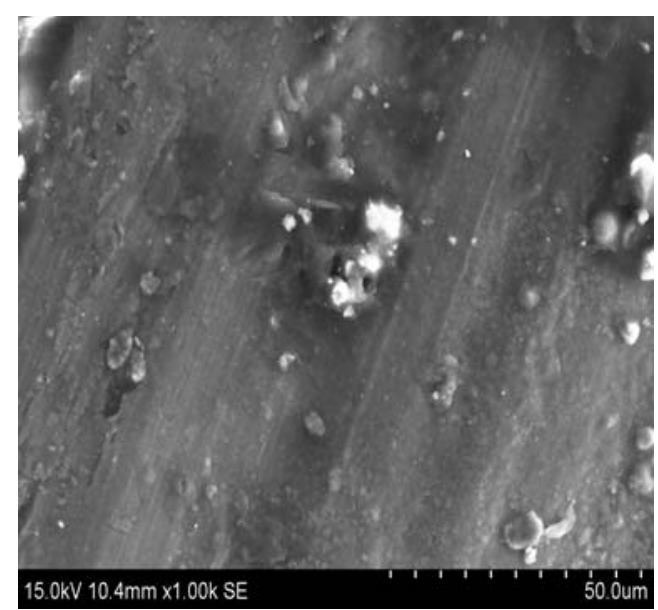

Figure 3. SEM microphotographs of Al-4.5wt\% Cu alloy reinforced fly ash

\subsection{Hardness}

Comparing the hardness of both gravity and squeeze casting of base alloy and composites, it was found from Figure 4 that by increasing the $\mathrm{wt} \%$ of fly ash, the hardness gradually increased. The squeeze casting of base alloy exhibit higher hardness when compare to gravity casting. The gravity casting exhibit a hardness of $84 \mathrm{BHN}$ and the same alloy when squeezed to a pressure of $120 \mathrm{MPa}$ has a hardness of $92 \mathrm{BHN}$ which is almost $9.7 \%$ increase in hardness of squeezed specimen. This is due to the applied pressure during squeeze which gives homogeneous crystal structure and dendrite arms were broken down and fine-grained equiaxed microstructure will obtained by squeeze casting. The squeeze cast $\mathrm{Al}-4.5 \mathrm{wt} \% \mathrm{Cu}$ alloy reinforced $3,6,9$ and $12 \% \mathrm{wt}$. MMCs shows an hardness of 96, 104, 110 and 119BHN respectively, which indicates that reinforcement of fly ash particles increases the hardness value. This is in agreement with published literature, where Guo et al., (1998) and Murthy et al., (2012) observed an increase in hardness by adding fly ash particles in Al-matrix. The dispersion of fly ash particles enhances the hardness, as particles are harder than Al-Cu alloy; the materials render their inherent property of hardness to the soft matrix. This can be attributed primarily due to the presence of relatively harder fly ash walls in the matrix and higher constraint to the localized matrix deformation during indentation, due to the presence of fly ash particles (Rohatgi et al., 2009).

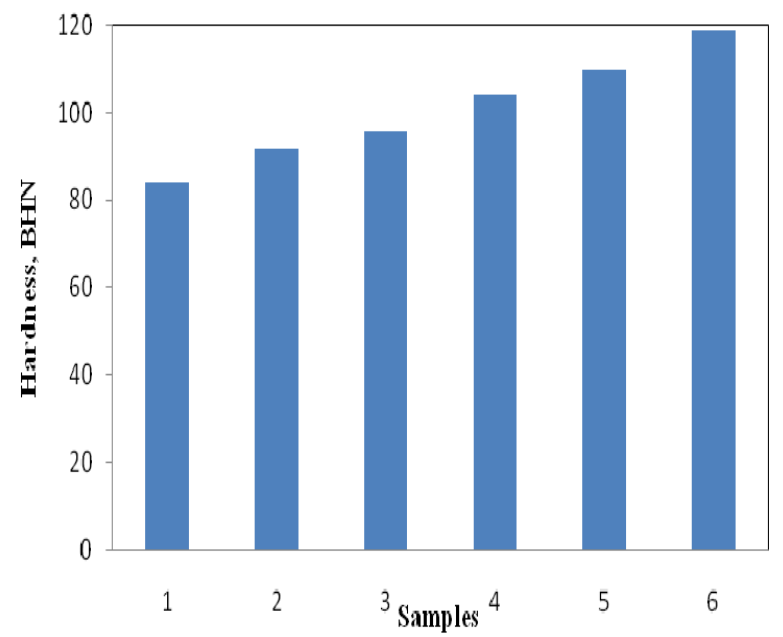

Figure 4. Hardness of gravity, squeeze cast of base alloy and composite

\subsection{Tensile strength}

The influence of fly ash particles content on the Ultimate tensile strength (UTS) of the MMC is shown in Figure 5. It was noted that the UTS increases with the addition of fly ash particles. The UTS shows the peak value of $163 \mathrm{MPa}$ for $12 \mathrm{wt} \%$ fly ash and shows an increase of strength to $32.5 \%$ when compared to squeeze cast of base alloy. This is due to the hard and lighter microsphere of fly ash, which act as barriers to the movement of dislocation and refines the structure of matrix and this is in par with literature Suresh et al., (2010). 


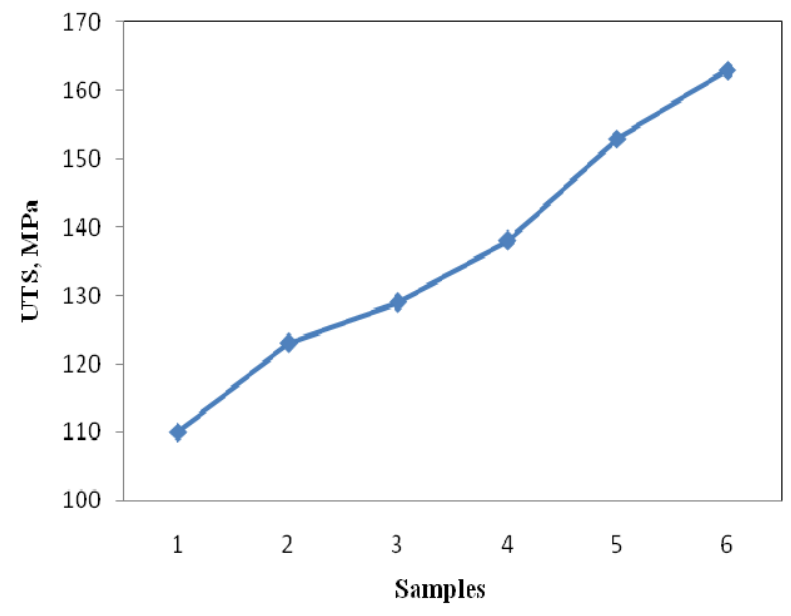

Figure 5. Variation of gravity cast, squeeze cast and fly ash composite on Ultimate tensile strength

Similarly the UTS of squeeze cast base alloy are $123 \mathrm{MPa}$ and that of gravity cast is $110 \mathrm{MPa}$ which is $11.8 \%$ increase in strength. This could be due to the applied pressure while squeezing. The applied pressure attributed to eliminating of micro-pores in the alloy and microstructure refining enhancement of solubility of solute and is reported by Li et al., (2010).

The tensile fracture of fly ash particulates can be seen in the SEM microphotograph of $12 \mathrm{wt} \%$ fly ash composite (Figure 6) resulting in a finer grain structure of the castings due to squeeze pressure. It should be noted that other factors such as the grain refinement and strain hardening by dislocations may also contribute to increasing the strength by squeezing the molten metal. The two regions are visible on the surface where a flat surface located around fly ash particles and on area in the matrix including fine dimples. All fly ash particles were broken by brittle mechanism and it is the combination of soft mechanism in matrix due to which formation of dimples and a cleavage mechanism around and inside of fly ash precipitates. There are still some cracks visible inside the fly ash fracture and this proved that, during tensile test, more than one crack is formed in the bulk of fly ash particle and finally one of them leads to breakdown of fly ash particles. The formation of flat area around the fly ash particle on fracture surface is due to the growth of cracks in fly ash particle into the matrix.

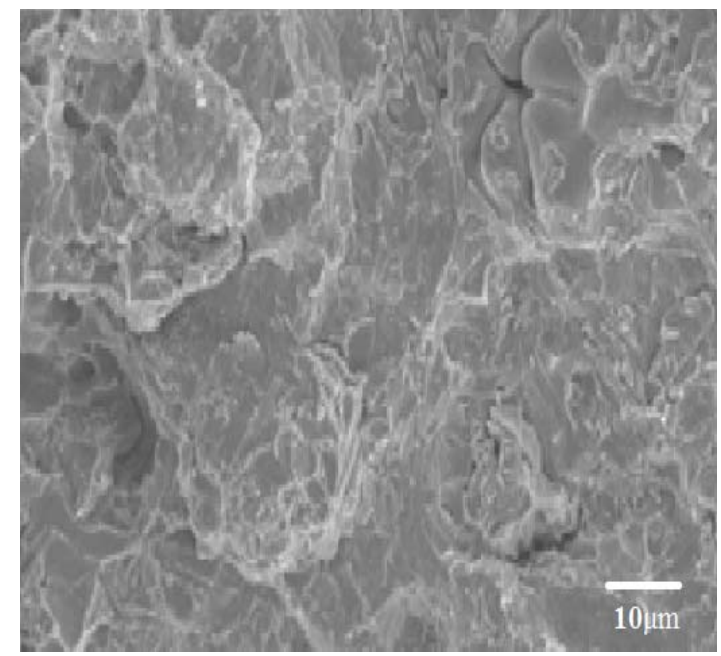

Figure 6. Fractured surface of squeeze cast tensile specimen composite

\subsection{Compression strength}

Figure 7 shows the results obtained from uniaxial compression as a function of fly ash particulate. Increase in percentage of fly ash increases the compression strength of composites. This is due to the hardening of the base alloy by fly ash particulates. 


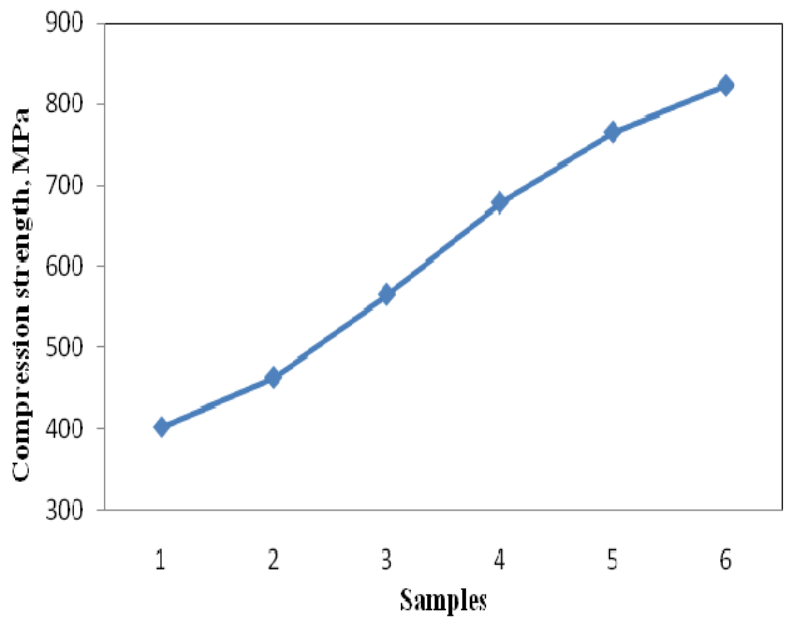

Figure 7. Variation of gravity cast, squeeze cast and fly ash composite on Compression strength

The fly ash reinforcement has highest weight percentage and this may increase the density of the material which cause in increase in compressive strength. The application of pressure during solidification in squeeze casting minimizes porosity and makes the metal denser, making the matrix to resist surfacial plastic deformation, rendering higher strength to the matrix. The squeeze cast base alloy exhibit higher compression strength compared to gravity cast and this may be due to compaction pressure applied during squeeze made the casting finer grain size and low porosity.

\subsection{Impact strength}

From Figure 8 the impact strength also increases with increasing fly ash content. This may be due to the presence of hard fly ash particulates.

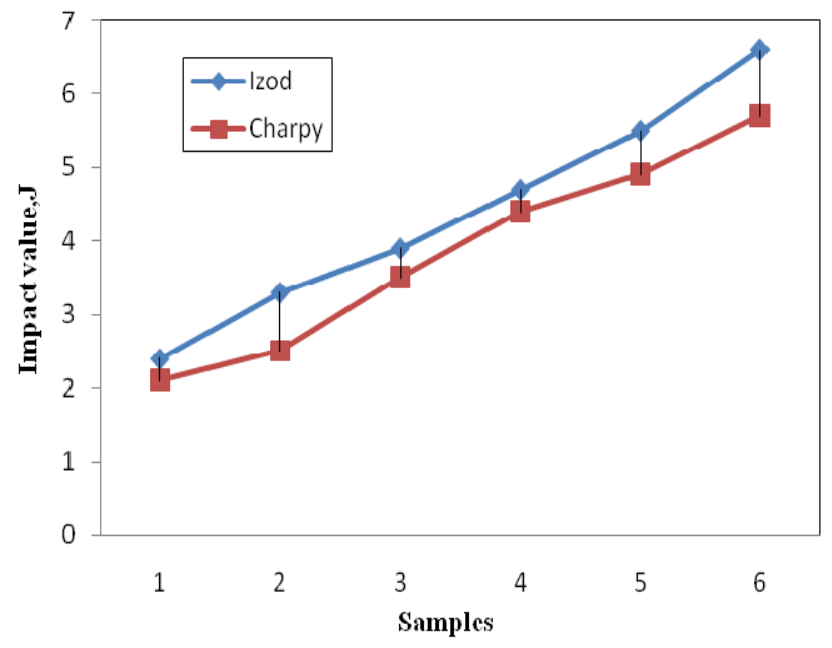

Figure 8. Izod and Charpy impact strengths of gravity cast, squeeze cast and fly ash composite

The impact strength shows higher values for $12 \mathrm{wt} \%$ fly ash composites than the base alloy. The squeeze cast base alloy exhibit higher impact value than gravity cast and this is due to application of pressure during solidification results in refined grain structure of the base alloy. The trend of both izod and charpy remains almost same, which is in par with literature Mahendra et al., (2007).

\section{Conclusions}

The hardness of squeeze cast matrix alloy increased from 84 to $92 \mathrm{BHN}$ with the applied pressure of 120MPa. In the composites hardness increased with increasing percentage of fly ash with the recorded value of $119 \mathrm{BHN}$ for $12 \mathrm{wt} \%$ fly ash composite. The ultimate tensile strength of squeeze cast samples increases with increase in percentage of fly ash. The gravity cast base alloy has lower UTS when compare to squeeze cast base alloy and composites. SEM shows good bonding of flyash particles with matrix. 
Probably this may be the reason due to which there is increase in hardness and tensile strength. Density decreases from 2.7714 to $2.7112 \mathrm{~g} / \mathrm{cm}^{3}$ with increase percentage of fly ash. Porosity on the other hand is higher for gravity cast and lower for squeeze cast matrix alloy. Impact strength is higher for higher percentage of flyash reinforcement. Out of all squeeze cast composites, $12 \mathrm{wt} \%$ fly ash reinforced sample reveal $4.35 \%$ porosity which is lesser than gravity cast matrix alloy. Optical microphotographs show the uniform dispersion of the reinforcements in MMCs with good bonding between the matrix and reinforcements. The composite produced by squeeze casting shows lower porosity and higher compression strength. This composite can be used for rolling applications where the existing rolled components of different materials may be replaced with this composite.

\section{Acknowledgements}

The work described in this paper was supported by Research Centre of Acharya Institute of Technology, Bangalore and BMS College of Engineering Bangalore, India. A support from the Jyothy Institute of Technology, Bangalore, is also acknowledged.

\section{References}

Abtan N.S., 2007. A study on squeeze casting parameters effects on improving the metallurgical and mechanical properties of aluminum alloys, Ph.D. thesis, Dept. of Production Engineering and Metallurgy, University of Technology, Baghdad, Iraq.

Dhadse S., Kumari.P., Bhagia L.J., 2008. Fly ash characterization utilization and government initiatives in India -Review, Journal of Scientific and Industrial Research, Vol. 67, pp.11-18.

Guo R.Q., Rohatgi P.K. 1998. Chemical reactions between aluminum and fly ash during synthesis and reheating of aluminum-fly ash composite. Metallurgical and Materials Transaction B, Vol. 29, pp.519-525.

Hashim J., Looney L., Hashmi M.S.J., 2001. The enhancement of wettability of SiC particles in cast aluminium matrix composites, Journal of Material Processing Technology, Vol. 119, pp. 329-335.

Ibrahim A, Mohamed FA, Lavernia F.J. 1991. Particulate reinforced metal matrix composites- a review, Journal of Material Science, Vol. 26, pp.1137-1156.

Klimowicz T.F., 1994. The large scale commercialization of aluminum-matrix composites, Journal of the Minerals, Metals and Materials Society, Vol. 46, pp. 49-53.

Kretschmer J. 1988. Overview: composites in automotive applications, state of the art and prospects. Material Science Technology, Vol. 4, No. 9, pp. 757-767.

Li R.-X., Li R. -D., Bai Y.-H., Qu Y.-D., Yuan X.-G., 2010. Effect of specific pressure on microstructure and mechanical properties of squeeze casting of ZA27 alloy, Transaction of Nonferrous Metals Society of China, Vol. 20, pp.59-63.

Mahendra K.V., Radhakrishna K., 2007. Fabrication of Al-4.5\% Cu alloy with fly ash metal matrix composites and its characterization, Materials Science-Poland, Vol. 25, No. 1, pp.57-68

Meyers M.A., Chawla K.K., 1999. Mechanical behavior of materials, Prentice-Hall, Inc., USA, pp. 644.

Murthy I. N., Rao D.V., Rao J.B., 2012. Microstructure and mechanical properties of aluminum-fly ash nano composites made by ultrasonic method, Materials and Design Vol. 35, pp.55-65.

Ogel B., Gurbuz R., 2001. Microstructural characterization and tensile properties of hot pressed Al-Sic composites prepared from pure $\mathrm{Al}$ and $\mathrm{Cu}$ powders Material Science and Engineering: A. Vol. 301, pp.213-220.

Onat A., Akbulut H., Yilmaz F., 2007. Production and characterization of silicon carbide particulate reinforced aluminium-copper alloy matrix composites by direct squeeze casting method, Journal of Alloys and Compounds, Vol. 436, pp. 375-382.

Rohatgi P. K., Guo R. R., 1997. Opportunities of using fly ash particles for synthesis of composites, Proceedings of the $59^{\text {th }}$ Annual American Power Conference, Chicago, p. 828.

Rohatgi P.K., D. Weiss, and N. Gupta, 2006. Applications of fly ash in synthesizing low-cost MMCs for automotive and other applications, Journal of the Minerals, Metals \& Materials Society, Vol. 58, No. 11, pp. 71-76.

Rohatgi P.K., Daoud A., Schultz B.F., Puri T., 2009. Microstructure and mechanical behavior of die casting AZ91D-Fly ash cenosphere composites, Composites: Part A, Vol. 40, pp. 883-896

Shorowordi K.M., Laoui T., Haseeb A.S.M.A., Celis J.P., Froyen L., 2003. Microstructure and interface characteristics of $B_{4} C$, $\mathrm{SiC}$ and $\mathrm{Al}_{2} \mathrm{O}_{3}$ reinforced $\mathrm{Al}$ matrix composites, Journal of Material Processing Technology, Vol. 142, pp. 738-743.

Surappa M K., 1997. Microstructure evolution during solidification of DRMMCs: state of art, Journal of Material Processing Technology, Vol. 63, pp. 325-333.

Suresh K.R., Niranjan H.B., Jebaraj P.M., Chowdiah M.P., 2003. Tensile and wear properties of aluminum composites, Wear, Vol. 255, pp. 638-642.

Suresh N., Venkateswaran S., Seetharamu S., 2010. Influence of cenospheres of fly ash on the mechanical properties and wear of permanent moulded eutectic Al-Si alloys, Materials Science-Poland, Vol.28, No.1, pp.55-65. 


\section{Biographical notes}

G. N. Lokesh received M. Tech. from University B. D. T. College of Engineering, Karnataka, India in 2001. He is an Asst. Professor in the Dept. of Mechanical Engineering, Acharya Institute of Technology Bangalore-560107, India. He has more than 14 years of experience in teaching and research and presently he is pursuing part-time Ph.D. under Visvesvaraya Technological University, Belgaum, India. His research interests include characterization of Hybrid Metal Matrix Composites and its Secondary process. He has also presented more than fifteen research articles in national and international conferences and published many journals.

Dr. M. Ramachandra working as Professor in the Dept. of Mechanical Engineering, B.M.S. College of Engineering, Bangalore-560019, India. He is guiding more than five Ph.D. Research scholars and presented more than fifteen research articles in national, international conferences and many journals. His research interests include characterization of Metal Matrix Composites and Nano-composites using fly ash as reinforcements.

Dr. K.V. Mahendra working as a principal in Jyothy Institute of Technology, Kanakapura Road, Bangalore-560062, India. He is guiding more than seven Ph.D. Research scholars under Visvesvaraya Technological University, Belgaum. India. He has presented more than fifteen research articles in national and international conferences and published many journals. His research interests include characterization of Hybrid Metal Matrix Composites for automobile applications.

T. Sreenith is a student of M Tech. in the Dept. of Mechanical Engineering, Acharya Institute of Technology Bangalore-560107, India.

Received May 2013

Accepted June 2013

Final acceptance in revised form July 2013 